\title{
LOS ATENTADOS TERRORISTAS DE BARCELONA Y CAMBRILS EN LA PRENSA ONLINE. TRATAMIENTO INFORMATIVO EN EL PERIÓDICO, EL PAÍS Y THE GUARDIAN
}

\author{
The terrorist attacks in Barcelona and Cambrils in the \\ online press. Informative treatment in El periódico, \\ El pais and The guardian
}

Jesús Díaz-Campo, María-Ángeles Chaparro-Domínguez y Ruth RodríguezMartínez

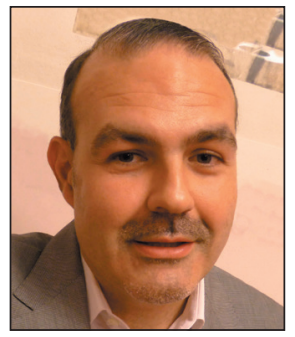

Jesús Díaz-Campo, doctor en Periodismo por la Universidad Complutense de Madrid, es profesor titular en la Universidad Internacional de la Rioja (UNIR) donde dirige el Master en Comunicación e Identidad Corporativa. Forma parte del grupo de investigación Comunicación y Sociedad Digital de UNIR. Tiene reconocido un sexenio de investigación. Sus áreas de interés son la ética de la comunicación, el periodismo digital y la comunicación política. Miembro del proyecto MediaACES. Accountability y culturas periodísticas en España. Impacto y propuesta de buenas prácticas en los medios de comunicación españoles (Mineco/Feder, UE, ref.: CSO2015-66404-P).

https://orcid.org/0000-0001-5014-8749

Universidad Internacional de la Rioja Avenida de la Paz, 137. 26006 Logroño, España jesus.diaz@unir.net

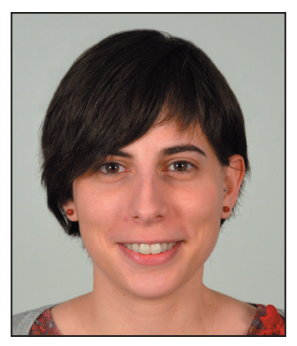

María-Ángeles Chaparro-Domínguez, doctora en Periodismo por la Universidad Complutense de Madrid, es profesora adjunta en la Universidad Internacional de La Rioja (UNIR), donde dirige el Master en Periodismo de Investigación, Datos y Visualización. Tiene reconocido un sexenio de investigación. Forma parte del grupo de investigación Comunicación y Sociedad Digital de UNIR y es miembro del proyecto MediaACES. Accountability y culturas periodísticas en España. Impacto y propuesta de buenas prácticas en los medios de comunicación españoles (Mineco/Feder, UE, ref.: CSO2015-66404-P). Sus principales líneas de investigación son el periodismo de datos, las redes sociales y los nuevos medios.

https://orcid.org/0000-0001-7750-3755

Universidad Internacional de la Rioja Avenida de la Paz, 137. 26006 Logroño, España marian.chaparrodominguez@unir.net

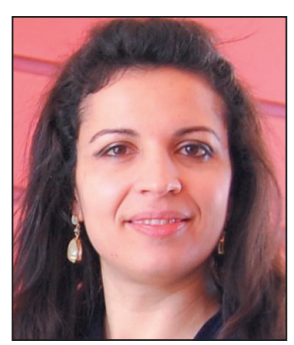

Ruth Rodríguez-Martínez, doctora en Periodismo por la Universidad Complutense de Madrid, es profesora en el Departamento de Comunicación de la Universitat Pompeu Fabra (UPF) y miembro del Grup de Recerca en Periodisme de la UPF. Sus principales líneas de investigación son el periodismo cultural, la ética en los medios, y el periodismo digital. Ha participado en proyectos de investigación financiados por el Ministerio de Economía y Competitividad de España y la Comisión Europea. Es investigadora principal del proyecto de investigación MediaACES. Accountability y culturas periodísticas en España. Impacto y propuesta de buenas prácticas en los medios de comunicación españoles (Mineco/Feder, UE, ref.: CSO2015-66404-P).

https://orcid.org/0000-0001-5633-6126

Universitat Pompeu Fabra Roc Boronat, 138. 08018 Barcelona, España ruth.rodriguez@upf.edu

\section{Resumen}

Se analiza la cobertura periodística de los atentados terroristas que se produjeron en Barcelona y Cambrils en agosto de 2017 en las ediciones online de tres diarios de referencia internacional (The guardian), en España (El país) y en Cataluña (EI periódico de Cataluña). Se compara el contenido que publicaron con los criterios del Código Deontológico del Col·legi de 
Periodistes de Catalunya y las Recomendaciones sobre la cobertura informativa de actos terroristas del Consell de l'Audiovisual de Catalunya (CAC-CPC, 2016). Los resultados muestran que en general los diarios cumplen estos criterios, con las excepciones de la protección de los derechos de los menores y el derecho al respeto a la privacidad.

\title{
Palabras clave
}

Periodismo; Terrorismo; Ética periodística; Códigos deontológicos; Prensa digital; Protección de los menores; Privacidad; Conflictos de interés.

\begin{abstract}
This article is focused on the media coverage of the terrorist attacks occurred in Barcelona and Cambrils, Spain, in August 2017. The study analyzes the digital version of three international newspapers: The guardian, El país and El periódico de Catalunya. The content they published is compared with the Code of Ethics of the Professional Journalists Association of Catalonia and the Guidelines on news coverage of terrorism from the Catalan Audiovisual Council (CAC-CPC, 2016). The results show that the newspapers meet these criteria, with the exceptions of the protection of minors and the protection of privacy.
\end{abstract}

\section{Keywords}

Journalism; Terrorism; Media ethics; Code of ethics; Digital media; Protection of minors; Protection of privacy; Conflicts of interest.

Díaz-Campo, Jesús; Chaparro-Domínguez, María-Ángeles; Rodríguez-Martínez, Ruth (2018). "Los atentados terroristas de Barcelona y Cambrils en la prensa online. Tratamiento informativo en El periódico, El país y The guardian". El profesional de la información, v. 27, n. 6, pp. 1358-1367.

https://doi.org/10.3145/epi.2018.nov.18

\section{Introducción}

La relación entre terrorismo y medios de comunicación puede definirse como compleja y delicada (Cohen-Almagor, 2005). Por un lado, los terroristas ven en los medios un altavoz para publicitar sus actuaciones violentas, sus aspiraciones y su propia existencia (Hoskins; Awan; O'Loughlin, 2011; Merolla; Zechmeister, 2009; Nacos, 1994), por lo que al planificar sus ataques tienen en cuenta las rutinas periodísticas (Mathews, 2016; Seib; Janbek, 2010; Spencer, 2010). Algunos autores apuntan incluso que los medios se convierten en aliados de los terroristas porque amplifican el drama de sus acciones (Barnett; Reynolds, 2009).

Por su parte, los medios argumentan que estas informaciones generan gran interés y su obligación es informar, por lo que el silencio no es una opción (Houston, 2009; Rivas-Nieto; Plaza, 2015). De hecho, los actos terroristas se convierten por su naturaleza en eventos mediáticos (Dayan; Katz, 1992), caracterizados por el dramatismo y las historias personales de los damnificados (Weimann, 1987; Yarchi; Galily; Tamir, 2015) ante una población en estado de crisis (Mogensen, 2008) y para la que lo emocional adquiere gran relevancia (Shoshani; Slone, 2008). Una situación definida como "teatro del terror" (Weimann, 1983) o "terrorismo mediatizado" (Nacos, 2002), en la que existen héroes y villanos (Anker, 2005), una planificación, un guion y una coreografía, buscando la mayor exposición posible con la complicidad de los medios (Weimann; Winn, 1994).

Los atentados del 11 de septiembre de 2001 en Estados Unidos supusieron un antes y un después en la cobertura periodística del terrorismo, pues adquirieron una dimensión internacional que aumentó el interés informativo (Cali, 2002; Sánchez-Duarte, 2009). Este carácter global se ha repetido en atentados posteriores como el de Noruega en 2011 o el ataque contra el semanario Charlie hebdo en Francia en 2015, entre otros (Cali, 2002; Marthoz, 2017) y se ha visto ampliado ante la nueva realidad del periodismo digital, caracterizado entre otros elementos por el papel activo de las audiencias (Rodríguez-Martínez et al., 2017) o el mayor protagonismo de las fuentes no oficiales (Bennett, 2016), que incluso pueden llegar a alterar el concepto de valores noticiosos (Konow-Lund; Olsson, 2017) y que exigen un replanteamiento de los principios éticos (Cruz-Álvarez; Suárez-Villegas, 2017; Díaz-Campo; Segado-Boj, 2015; Nacos, 2016; Seib, 2016; Suárez-Villegas, 2015a; Weimann, 2008).

Los atentados del 11 de septiembre de 2001 en Estados Unidos supusieron un antes y un después en la cobertura periodística del terrorismo por la dimensión internacional que adquirieron

Esa dimensión global está intrínsecamente ligada a otro debate: la posición de los medios ante un ataque (Cohen-Almagor, 2005). Varios autores advierten que el carácter traumático y el componente emocional de los hechos genera un sentimiento de compasión y solidaridad basado en la empatía y en la idea de sobrellevar el dolor compartiéndolo (Schudson, 2002; Keinan; Sadeh; Rosen, 2003), pero que no implica que la población comprenda los hechos ni se plantee tomar alguna iniciativa o acción práctica (Höijer, 2004; Tester, 2001). Así, los medios tienden a abandonar la objetividad para tomar partido y asumir la versión oficial de las instituciones sin contrastarla o plantearse posibles conflictos de interés (Moeller, 2009; Nagar, 2010; Norris; Montag- 
ne; Just, 2003; Nossek, 2008; Paletz; Schmid, 1992). Además, no existen diferencias al respecto entre los medios de distintos lugares (Yarchi; Galily; Tamir, 2015).

El colectivo periodístico trata de abordar estas y otras cuestiones mediante los mecanismos de autorregulación, en particular códigos deontológicos y consejos de prensa. Si bien los códigos ya incluyen recomendaciones en esta línea, como respetar el honor y la intimidad o evitar fomentar la violencia (Barroso, 1984; Díaz-Campo, 2006; Jones, 1980; Laitila, 1995), tras el 11-S se comprueba que esos principios generales necesitan ser complementados por documentos más específicos que hasta entonces existían esporádicamente, como una monografía sobre violencia y terror en los medios editada por Unesco (Gerbner, 1988). Así, un análisis posterior a los atentados (Keith; Schwalbe; Silcock, 2006) reveló que de 47 códigos de ética en Estados Unidos, solamente 9 contenían directrices para tratar imágenes trágicas y violentas. Por ello, desde ese momento proliferaron las recomendaciones a nivel internacional, entre las que destaca la monografía editada por Unesco (Marthoz, 2017).

En España, los atentados del 11 de marzo de 2004 tuvieron un efecto similar, dando lugar a estudios monográficos (por ejemplo, Vara et al., 2006) y a recomendaciones específicas (Consejo Deontológico de la FAPE, 2005; CAC, 2004). En su análisis sobre el tratamiento televisivo de los atentados, el Consell catalán destacó su carácter excepcional y abogó por mantener la pluralidad y la imparcialidad y respetar la privacidad, especialmente de los menores.

En el caso de la Comisión de Arbitraje, Quejas y Deontología del Periodismo de la Federación de Asociaciones de la Prensa de España (FAPE), considerada como uno de los principales referentes en materia de autorregulación del periodismo en España (Suárez-Villegas, 2015b), bajo su denominación original de Consejo Deontológico, dedicó su primera resolución a esta cuestión. El documento recomienda (Consejo Deontológico de la FAPE, 2005):

- subordinar el derecho de informar al respeto a la dignidad, la propia imagen, la intimidad y privacidad;

- rechazar explícitamente cualquier expresión de violencia;

- evitar intromisiones gratuitas y especulaciones;

- dar un trato especial a los afectados directa o indirectamente $y$, como norma general, evitar emplear imágenes de víctimas;

- tratar con especial cuidado a menores afectados;

- evitar la discriminación y la criminalización de parientes y amigos de presuntos terroristas;

- no utilizar con fines comerciales estas cuestiones.

Una nueva resolución (Comisión de Quejas y Deontología de la FAPE, 2008), que tomaba como referencia la de 2005, los códigos deontológicos de FAPE, del Col-legi de Periodistes de Catalunya y el código europeo, incidía nuevamente en respetar la privacidad y recomendaba evitar intromisiones gratuitas y especulaciones innecesarias. La Comisión de la FAPE ahondó en una resolución posterior, a propósito de un reportaje sobre una catástrofe ferroviaria en Santiago de Compostela, en el tratamiento de la infancia, señalando que a pesar de la especial protección de la que goza ese colectivo, cuando prima el mensaje informativo, prevalece el derecho a la información (Comisión de Quejas y Deontología de la FAPE, 2013).

Mientras, las Recomendaciones éticas o deontológicas para el tratamiento periodístico y mediático de las catástrofes (Comisión de Quejas y Deontología de la FAPE, 2014), redactadas a petición de la Asociación de la Prensa de Madrid, ratificaban que las consideraciones realizadas en 2005 seguían estando vigentes.

El documento más reciente son las Recomendaciones sobre la cobertura informativa de actos terroristas (CAC-CPC, 2016), estructuradas en cinco apartados:

- el primero, sobre los terroristas, aborda cuestiones como autoría, difusión de su identidad, tratamiento de contenidos suministrados por ellos, contextualización, adjetivación, tratamiento de sus familiares o la relación con los cuerpos de seguridad;

- el apartado relativo a las víctimas trata su identidad y la privacidad de fallecidos, supervivientes, menores y personas vulnerables;

- el apartado dedicado a la audiencia analiza las fuentes informativas, la advertencia de emisión de imágenes duras, la espectacularización, las imágenes de archivo o el uso de material generado por usuarios;

- los dos apartados finales se dedican a periodistas y autoridades, y abordan la relación entre ambos.

Por tanto, en general, las directrices éticas que incluyen los distintos documentos siguen una línea similar con independencia del ámbito geográfico o el organismo del que hayan partido.

\section{Las directrices éticas para la cobertura} de actos terroristas son, en general, muy similares con independencia del lugar en el que se hayan elaborado

\section{Metodología}

Se ha utilizado el análisis de contenido cualitativo, que permite interpretar de forma sistemática y exhaustiva las piezas seleccionadas. Se ha comparado el contenido publicado por los diarios analizados con los criterios establecidos en el Código deontológico del Col-legi de Periodistes de Catalunya (CPC-CIC, 2006) y las Recomendaciones sobre la cobertura informativa de actos terroristas (CAC-CPC, 2016) ${ }^{1}$. La elección de estos dos documentos responde a que ambos recogen las principales pautas y recomendaciones que deben seguir los periodistas en este tipo de coberturas para garantizar que la información publicada se ajuste a principios éticos fundamentales (Almirón; Narberhaus; Mauri-Ríos, 2016; Rodríguez-Martínez et al., 2017).

Tomando como punto de partida estas pautas, se generaron plantillas de análisis textual del discurso que han permitido determinar su cumplimiento o no en los diarios. Las observaciones, ejemplos y enlaces incluidos en cada plantilla permiten comprobar el grado de cumplimiento respecto a estas prescripciones. Se incluye la descripción de piezas informativas que presentan características diferentes a las previstas en las plantillas. 
Tabla 1. Lista de categorías utilizadas en la investigación. Estas categorías han sido desarrolladas a partir de los criterios incluidos en el Código deontológico del Col-legi de Periodistes de Catalunya y las Recomendaciones sobre la cobertura informativa de actos terroristas del CAC-CPC

\begin{tabular}{|c|c|}
\hline $\begin{array}{l}\text { Código deontológico - Declaración de principios de la profesión periodística } \\
\text { en Cataluña }\end{array}$ & $\begin{array}{l}\text { Recomendaciones sobre la cobertura informativa de actos } \\
\text { terroristas }\end{array}$ \\
\hline 01. Informar de manera cuidadosa y precisa & $\begin{array}{l}\text { 1.1. Autoría } \\
\text { 1.4. Contextualización }\end{array}$ \\
\hline \multicolumn{2}{|l|}{ 02. Evitar perjuicios por informaciones sin suficiente fundamento } \\
\hline \multicolumn{2}{|l|}{ 03. Rectificar las informaciones incorrectas } \\
\hline \multicolumn{2}{|l|}{ 04. Utilizar métodos lícitos y dignos para obtener información } \\
\hline 05. Citar las fuentes y preservar el secreto profesional & $\begin{array}{l}\text { 1.7. Relación con los cuerpos de seguridad } \\
\text { 3.1. Fuentes informativas }\end{array}$ \\
\hline 06. Conciliar los derechos individuales con el derecho del público a saber & 3.2. Advertencia sobre la dureza extrema de las imágenes \\
\hline \multicolumn{2}{|l|}{ 07. Evitar el conflicto de intereses } \\
\hline \multicolumn{2}{|l|}{ 08. No utilizar en provecho propio informaciones privilegiadas } \\
\hline 09. Respetar el derecho a la privacidad & $\begin{array}{l}\text { 1.6. Familiares de la persona autora de un acto terrorista } \\
\text { 2.1. Identidad de las víctimas } \\
\text { 2.2. Privacidad de las víctimas mortales } \\
\text { 2.3. Privacidad de las víctimas supervivientes } \\
\text { 2.5. Víctimas de actos terroristas anteriores }\end{array}$ \\
\hline 10. Salvaguardar la presunción de inocencia & 1.2. Tratamiento de la identidad de los terroristas \\
\hline 11. Proteger los derechos de los menores & 2.4. Menores de edad y personas vulnerables \\
\hline \multicolumn{2}{|l|}{ 12. Respetar la dignidad de las personas y su integridad física y moral } \\
\hline \multicolumn{2}{|l|}{ Anexo A. Recomendación sobre manipulación de imágenes } \\
\hline Anexo B. Recomendación sobre internet & $\begin{array}{l}\text { 3.8. Uso periodístico del material audiovisual generado por los } \\
\text { usuarios }\end{array}$ \\
\hline \multicolumn{2}{|l|}{ Anexo C. Recomendación sobre el plagio } \\
\hline \multicolumn{2}{|l|}{ Anexo D. Recomendación sobre el tratamiento de conflictos bélicos o armados } \\
\hline \multicolumn{2}{|l|}{ Anexo E. Recomendación sobre el uso del término “ilegales” referido a personas } \\
\hline Anexo F. Recomendación sobre la cita de nacionalidades y etnias & 1.5. Adjetivación del terrorismo \\
\hline Otras observaciones relevantes & $\begin{array}{l}\text { 1.3. Tratamiento de contenidos subministrados por terroristas } \\
\text { 1.7. Relación con los cuerpos de seguridad } \\
\text { 3.4. Espectacularización del lenguaje verbal }\end{array}$ \\
\hline
\end{tabular}

Cabe señalar como limitaciones de esta metodología, que algunas cuestiones relativas al proceso de producción de la noticia, como el uso de la información en provecho propio o la preservación del secreto profesional, se pueden determinar pero solamente hasta cierto punto, y no de manera exhaustiva, algo que requeriría una investigación más profunda que incluyese entrevistas a los propios profesionales.

En referencia a la muestra utilizada, se han elegido los sitios web de los siguientes diarios:

- El periódico de Cataluña https://www.elperiodico.com/es

- El país

http://elpais.com

\section{- The guardian https://www.theguardian.com/international}

Dicha selección permite observar el tratamiento de los atentados ocurridos en Barcelona y Cambrils en diarios de referencia del contexto catalán, español e internacional. Se pueden, de esta manera, identificar los aspectos en los que los tres diarios realizan una cobertura semejante y aquellos en los que difieren. La pertinencia de incluir un diario internacional viene dada porque se trata de un atentado perpetrado por un grupo terrorista que opera a nivel internacional.

En cuanto al período de estudio, se han seleccionado todas las noticias publicadas por esos tres medios en las 24 horas posteriores a los atentados ocurridos en las Ramblas de Barcelona y Cambrils el 17 y 18 de agosto de 2017. Se han recuperado las noticias a través del buscador de Google. En total, se han analizado 21 piezas publicadas por El periódico de Cataluña, 27 de El país y 26 de The guardian. Por ello ha sido importante detectar los criterios éticos más vulnerables en situaciones de crisis. Por otro lado, la elección de los sitios web frente a las versiones impresas 
Tabla 3. Análisis del cumplimiento de las recomendaciones del Col/legi de Periodistes de Catalunya por los diarios analizados.

\begin{tabular}{|c|c|c|c|}
\hline Recomendación & El país & El periódico & The guardian \\
\hline Informar de manera cuidadosa y precisa & $\mathrm{x}$ & $X$ & $\mathrm{X}$ \\
\hline Evitar prejuicios por informaciones sin suficiente fundamento & $\mathrm{X}$ & $\mathrm{X}$ & $\mathrm{X}$ \\
\hline Rectificar las informaciones incorrectas & - & - & $\mathrm{x}$ \\
\hline Utilizar métodos lícitos y dignos para obtener información & - & $x$ & $x$ \\
\hline Citar las fuentes y preservar el secreto profesional & $X$ & $\mathrm{X}$ & $\mathrm{X}$ \\
\hline Conciliar los derechos individuales con el derecho público a saber & $X$ & - & $X$ \\
\hline Evitar el conflicto de intereses & - & $X$ & $\mathrm{x}$ \\
\hline No utilizar en provecho propio informaciones privilegiadas & $X$ & $X$ & $X$ \\
\hline Respetar el derecho a la privacidad & $\mathrm{X}$ & - & - \\
\hline Salvaguardar la presunción de inocencia & $x$ & $X$ & $X$ \\
\hline Proteger los derechos de los menores & - & - & - \\
\hline Respetar la dignidad de las personas y su integridad física y moral & $x$ & $x$ & $x$ \\
\hline Recomendación sobre manipulación de imágenes & $X$ & $X$ & $X$ \\
\hline Recomendación sobre internet & - & $\mathrm{x}$ & $\mathrm{x}$ \\
\hline Recomendación sobre el plagio & $\mathrm{X}$ & $\mathrm{x}$ & $x$ \\
\hline Recomendación sobre el tratamiento de conflictos bélicos o armados & $\mathrm{X}$ & $\mathrm{X}$ & $\mathrm{X}$ \\
\hline Recomendación sobre el uso del término "ilegales" referido a personas & $x$ & $\mathrm{X}$ & $\mathrm{x}$ \\
\hline Recomendación sobre la cita de nacionalidades y etnias & $x$ & $x$ & $x$ \\
\hline
\end{tabular}

X: cumplimiento

- : no se observa cumplimiento ni incumplimiento.

de los diarios hace posible analizar el contenido audiovisual publicado. Cabe destacar que el contenido multimedia (imágenes, galerías fotográficas, infografía, vídeos y otros recursos interactivos de producción propia o ajena a la redacción de los periódicos) ha sido fundamental para cumplimentar algunas de las categorías y observar ejemplos relevantes de buenas y malas prácticas.

\section{Análisis y resultados}

A grandes rasgos, los diarios analizados cumplen las recomendaciones del código deontológico del CPC y del CAC (tabla 3).

\subsection{Rigor, rectificación, fuentes y conflicto de intere- ses}

Este criterio establece que los medios tendrán que informar de manera precisa y cuidadosa, algo que cumplen los tres diarios. En The guardian las noticias se presentan con una contextualización adecuada, un estilo sobrio, preciso y $\sin$ adjetivos y con fuentes oficiales, testigos presenciales $u$ otros medios. En esta misma línea, El país recurre a expertos para contextualizar lo sucedido (Marcos, 2017) y El periódico ofrece siempre informaciones contrastadas, por ejemplo, en cuanto a la identidad de la persona que alquiló la furgoneta con la que se perpetró el atentado de Barcelona ( $E$ I periódico, 2017a).

El Código recomienda no utilizar expresiones injuriosas ni datos imprecisos que puedan lesionar o desacreditar a personas e instituciones. Los tres diarios cumplieron esta recomendación, como se aprecia, por ejemplo, en una noticia de El país que cubre la muerte de los cinco terroristas en Cambrils (García; Piñol; Güell, 2017).
En cuanto a la rectificación de informaciones incorrectas, en El país y El periódico no se observa ninguna. El diario catalán se hizo eco del supuesto atrincheramiento de los terroristas en un bar en Barcelona, algo desmentido y corregido por varios medios, entre los que no se incluyó El periódico. En cambio, una noticia de The guardian, incluye un apartado final en el que se rectifica la información publicada (Burke, 2017).

\section{Se han analizado las noticias publicadas por tres medios digitales de referencia en las 24 horas posteriores a los atenta- dos de Barcelona y Cambrils en agosto de 2017}

El uso de métodos lícitos y dignos para obtener la información es otra recomendación. La siguen tanto The guardian como El periódico en todas las informaciones. No sucede lo mismo con El país, que en una ocasión, poco después del atentado, subió a su web un audio de la policía de Barcelona donde se hablaba de la huida del conductor de la furgoneta y de las primeras víctimas. En la noticia no explican cómo consiguieron ese audio (El país, 2017a).

En cuanto a la obligación de citar las fuentes y preservar el secreto profesional cuando éstas lo soliciten, por lo general, todas las fuentes aparecen correctamente citadas en los tres diarios, aunque se observan excepciones como en la citada información (que resultó ser falsa) de El periódico sobre un presunto atrincheramiento de los terroristas en un bar de Barcelona, donde se mencionan "fuentes policiales" en genérico (Sánchez, 2017). 
Con respecto a la conciliación de los derechos individuales con el derecho del público a saber, en general esta recomendación la siguen los tres diarios, aunque no siempre avisan de la dureza extrema de las imágenes. Sí lo hacen The guardian y El país antes de algunos vídeos (Tremlett et al., 2017; El país, 2017c), pero no así en algunas de las imágenes o, en el caso del periódico británico, en las galerías.

\subsection{Conflicto de intereses}

Respecto al conflicto de intereses, el código establece que

"como normal general, los profesionales de la información han de evitar cualquier situación de conflicto de intereses, ya sea de ámbito político, comercial, económico, financiero o familiar, que ponga en cuestión la credibilidad e imparcialidad de su función" (CPC-CIC, 2006, p. 6).

En algún caso se publican fotografías donde se puede reconocer a las víctimas, algunas de ellas menores

El periódico y The guardian cumplen esta recomendación pero El país no. En su editorial del día 18 se observa como antepone sus intereses políticos (en contra del referéndum de Cataluña del 1 de octubre) a su imparcialidad ante un atentado terrorista:

"Un ataque de esta magnitud tiene que ser un aldabonazo que devuelva a la realidad a las fuerzas políticas catalanas que, desde el Govern, el Parlament o los movimientos por la independencia han hecho de la quimera secesionista la sola y única actividad de la agenda política catalana en los últimos años" (El país, 2017b).

En cuanto al uso de la información en provecho propio de los periodistas, no se observa en ninguno de los tres diarios.

\subsection{Privacidad, presunción de inocencia y menores}

En lo que se refiere al respeto del derecho a la privacidad,

ningún diario desvela la identidad de las víctimas en el período analizado pero sí que reproducen fotografías donde se las puede identificar, especialmente El periódico (2017b) y The guardian (2017).

Otra de las recomendaciones salvaguarda la presunción de inocencia, algo que cumplen los tres diarios analizados cuando se refieren a los supuestos terroristas. Por ejemplo, The guardian siempre incluye la palabra "suspect" para aludir a éstos (Tremlett et al., 2017). En cambio, el criterio que ninguno de los medios respeta es el que protege los derechos de los menores, ya que recogen fotografías donde éstos aparecen sin el consentimiento paterno (El periódico, 2017b). Además, no se debe difundir su identidad cuando están inculpados en causas criminales. Esto lo incumplió EI país, ya que publicó un reportaje que desvelaba la identidad de un menor y su fotografía porque era sospechoso de ser uno de los terroristas (García, 2017).

En ese mismo sentido, El periódico no respeta la recomendación sobre la dureza extrema de las imágenes y además publica fotografías donde se puede reconocer a las víctimas, algunas de ellas menores.

Respecto a la protección de la dignidad de las personas y su integridad física y moral, los tres diarios cumplen este criterio ya que no recogen ningún elemento discriminatorio ni que incite a la violencia en ninguno de los textos analizados (Marcos, 2017).

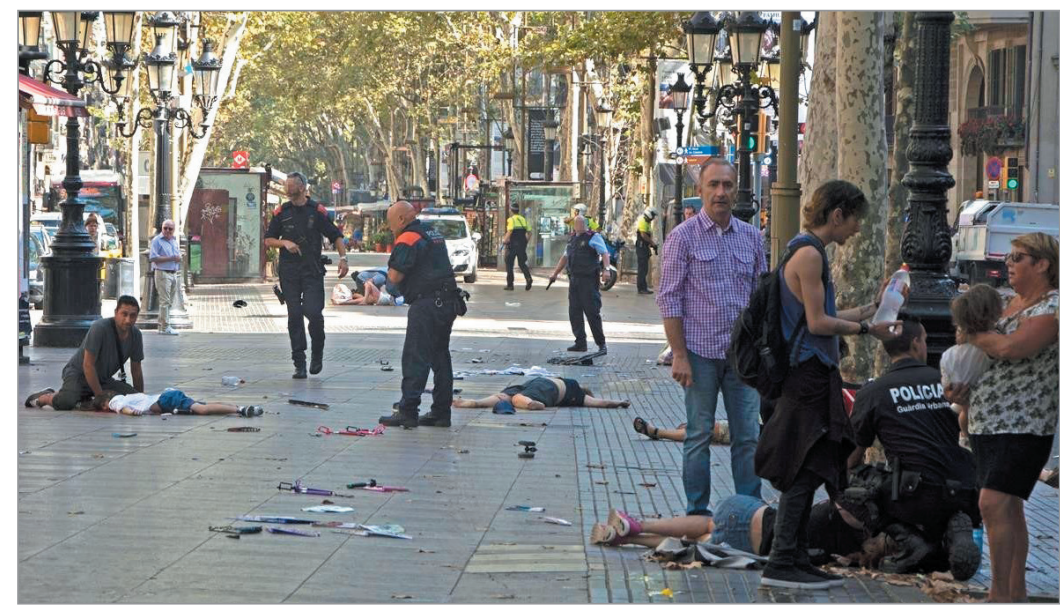

https://www.elperiodico.com/es/barcelona/20170817/fotos-atentado-barcelona$6229002 / f / 4142944$

\subsection{Imágenes, plagio y nacionalidades}

Entre los anexos del Código que hacen referencia a las imágenes, se aconseja identificar correctamente a los autores de fotografías publicadas y que éstas no se manipulen, algo que cumplen los tres diarios. Otro de los anexos incluye recomendaciones sobre prácticas en internet. Respecto al uso de material audiovisual generado por los usuarios, El periódico sólo utiliza contenidos de agencias o profesionales gráficos. The guardian sigue esta práctica salvo en una fotografía que extrae de un vídeo subido a Twitter (@pawilerma), que atribuye correctamente. En esta 


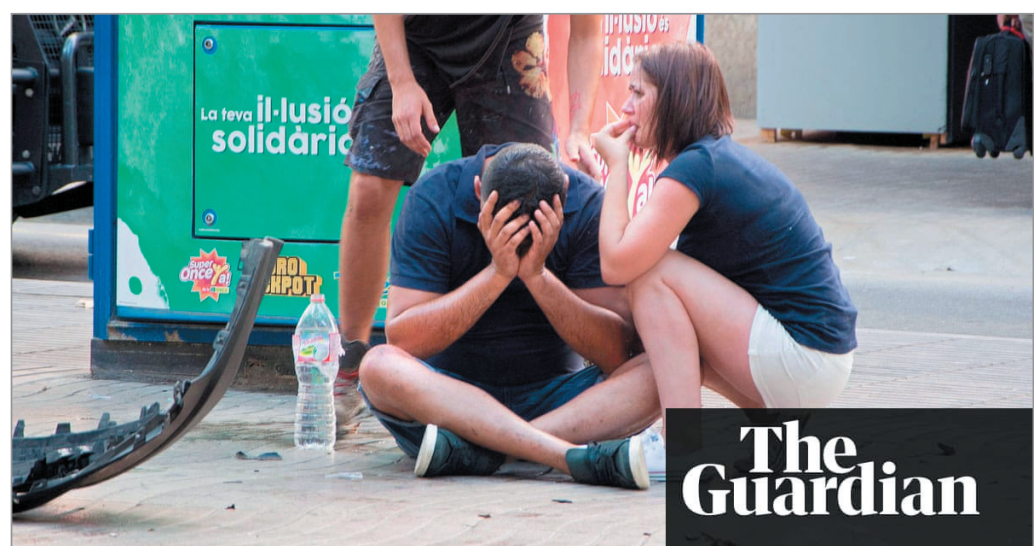

https://www.theguardian.com/world/gallery/2017/aug/17/barcelona-terror-attack-inpictures

\section{Discusión y conclusiones}

Los tres diarios analizados, a pesar de pertenecer a zonas geográficas diferentes, cumplen a grandes rasgos los criterios que se han tomado como referencia. La principal excepción a esta tendencia es la protección de los derechos de los menores, que no respeta ningún diario. Se trata de una cuestión relacionada con el respeto al derecho a la privacidad, que también incumplen dos diarios y, en la mayoría de casos, con el tratamiento de imágenes, que ya había sido detectado previamente como uno de los aspectos susceptibles de mayor regulación (Keith; Schwalbe; Silcock, 2006).

Como se ha mencionado, las principales recuenta de Twitter se puede observar cómo diversos medios ( $B B C, C B S, A F P$, Daily mirror o $A P$ ), contactaron con esta persona para poder utilizar sus fotos y vídeos (The guardian, 2017). El país, en cambio, publica un vídeo que parece ser de un turista anglosajón donde se ve cómo la policía tirotea a un terrorista de Cambrils pero no indica nada sobre autoría o procedencia (El país, 2017c).

Con respecto al plagio, a grandes rasgos, los tres diarios identifican correctamente las fuentes, así que no se aprecian casos de plagio. Otra recomendación tiene que ver con el tratamiento de conflictos bélicos y armados, para los que se recomienda tratarlos en profundidad, aportando causas y contexto. Esto es algo que desarrolla The guardian en varias piezas, donde puso en contexto el atentado de Barcelona con otros perpetrados por yihadistas en otras ciudades europeas en los meses anteriores y el de Madrid de 2004 (Burke, 2017; Badia-Dalmases, 2017; Jenkins, 2017).

Los tres medios cumplen a grandes rasgos los criterios éticos, con la principal excepción de los derechos de los menores y el derecho a la privacidad

Otra recomendación insta a evitar el uso del término "ilegal" referido a personas, algo que cumplen los tres diarios en todas sus informaciones. Por último, el Código deontológico pide ser especialmente cuidadosos al citar nacionalidades y etnias. The guardian menciona de manera explícita la nacionalidad de los terroristas pero en todas sus piezas hace referencia al terrorismo yihadista, no islámico (Burke, 2017). En la misma línea actúa El periódico, que se mostró cauto en la autoría al indicar que

"aunque la hipótesis principal sea la autoría yihadista no cabe descartar otras" (Núñez-Villaverde, 2017).

El país, por su parte, considera que la nacionalidad de los sospechosos es noticiable, por lo que cita la de todos ellos, tal y como recomienda el Código (El país, 2017d). Además, evita utilizar expresiones como "terrorismo islámico" o culpar a la religión musulmana de los atentados (Galán; Alameda, 2017; Marcos, 2017). comendaciones tras el análisis del tratamiento periodístico de los atentados del 11 de marzo de 2004, que también tuvieron lugar en España, iban justamente en la línea de salvaguardar los derechos de los menores (Consejo deontológico de la FAPE, 2005; CAC, 2004). Conviene recordar, por tanto, la necesidad de evitar la espectacularización de los contenidos, en tanto que la presencia de menores puede ayudar a dramatizar los hechos que se cubren.

En este sentido, resulta igualmente significativo que varios establecimientos y kioscos de Cataluña se negaron a vender ejemplares de algunos periódicos, ya que consideraban que las imágenes publicadas eran irrespetuosas con las víctimas. https://goo.gl/7Hi8UA

\section{Ningún diario recoge elementos discri- minatorios ni que inciten a la violencia en ninguno de los textos analizados}

Finalmente, este estudio podría replicarse en el futuro analizando la cobertura de otros atentados, lo que permitiría estudiar la evolución del tratamiento periodístico, prestando especial atención a imágenes y menores.

\section{Notas}

1. Uno y otro documento desarrollan en mayor profundidad los criterios que han de darse para establecer el cumplimiento de cada una de las recomendaciones, y que han seguido los autores para realizar este análisis. Los documentos se pueden encontrar en:

https://fcic.periodistes.cat/wp-content/uploads/2018/02/ codi-deontologic_CPC_CIC_castella\%CC\%80_BAIXA_GEN.pdf https://www.cac.cat/sites/default/files/2018-04/ Recomanacions_terrorisme_2_CA.pdf

\section{Agradecimientos}

Los resultados de este artículo han sido desarrollados en el marco del proyecto de investigación MediaACES. Accountability y culturas periodísticas en España. Impacto y propuesta de buenas prácticas en los medios de comunicación españoles, financiado por el Ministerio de Economía y Competitividad (Mineco/Feder, UE, ref.: CSO2015-66404-P) 
dentro del Programa estatal de fomento de la investigación científica y técnica de excelencia.

https://mediaaccountabilityspain.com

\section{Referencias}

Almiron, Núria; Narberhaus, Marta; Mauri-Ríos, Marcel (2016). "Mapping media accountability in stateless nations: The case of Catalonia". Catalan journal of communication \& cultural studies, v. 8, n. 2, pp. 207-225.

https://repositori.upf.edu/handle/10230/33237

https://doi.org/10.1386/cjcs.8.2.207_1

Anker, Elisabeth (2005). "Villains, victims and heroes: Melodrama, media, and September 11". Journal of communication, v. 55, n. 1, pp. 22-37.

https://americanstudies.columbian.gwu.edu/sites/g/files/ zaxdzs1806/f/downloads/Villians-JOC-Anker.pdf https://doi.org/10.1111/j.1460-2466.2005.tb02656.x

Badia-Dalmases, Francesc (2017). "The Barcelona I know will rise stronger after this day of horror". The guardian, August $18^{\text {th }}$.

https://www.theguardian.com/commentisfree/2017/ aug/18/barcelona-terror-attack-catalan-independence

Barnett, Brooke; Reynolds, Amy (2009). Terrorism and the press. An uneasy relationship. New York: Peter Lang. ISBN: 9780820495163

Bennett, Daniel (2016). "Sourcing the BBC's live online coverage of terror attacks". Digital journalism, v. 4, n. 7, pp. 861874.

http://sro.sussex.ac.uk/60633/

https://doi.org/10.1080/21670811.2016.1163233

Barroso, Porfirio (1984). Códigos deontológicos de los medios de comunicación. Madrid: Ediciones Paulinas. ISBN: 84 71513919

Burke, Jason (2017). "Nature of Las Ramblas attack provides harsh lessons in fight against terror". The guardian, August $17^{\text {th }}$ https://www.theguardian.com/world/2017/aug/17/nature-ofattack-in-las-ramblas-provides-harsh-lessons-in-fight-against-terror

CAC (2004). "Consideracions del Consell de l'Audiovisual de Catalunya sobre el tractament televisiu de l'atemptat de Madrid del dia 11 de març de 2004 i dels esdeveniments posteriors fins a les eleccions del dia 14". Quaderns del CAC, n. $19-20$, pp. $79-85$

https://www.cac.cat/sites/default/files/migrate/quaderns cac/Q19ambannex_ES.pdf

CAC-CPC (2016). Recomanacions sobre la cobertura informativa d'actes terroristes. Barcelona: Col-legi de Periodistes de Catalunya; Consell de l'Audiovisual de Catalunya. https://www.cac.cat/sites/default/files/2018-04/Recomanacions terrorisme_2_CA.pdf

Cali, Dennis D. (2002). “Journalism after September 11: Unity as moral imperative". Journal of mass media ethics, v. 17, n. 4, pp. 290-303.

https://doi.org/10.1207/S15327728JMME1704_04

Cohen-Almagor, Raphael (2005). "Media coverage of acts of terrorism: Troubling episodes and suggested guidelines".
Canadian journal of communication, v. 30, n. 3, pp. 383-409. https://www.cjc-online.ca/index.php/journal/article/ view/1579/1734

Comisión de Quejas y Deontología de la FAPE (2008). Recomendaciones acerca del tratamiento informativo de las situaciones catastróficas. Informe/Resolución 2008/24.

http://www.comisiondequejas.com/wp-content/uploads/24. $p d f$

Comisión de Quejas y Deontología de la FAPE (2013). Resolución 2013/75.

http://www.comisiondequejas.com/wp-content/ uploads/2015/09/75.pdf

Comisión de Quejas y Deontología de la FAPE (2014). Recomendaciones éticas o deontológicas para el tratamiento periodístico y mediático de las catástrofes. Informe/Resolución 2014/85. Febrero de 2014.

http://www.comisiondequejas.com/wp-content/ uploads/2015/09/85.pdf

Consejo Deontológico de la FAPE (2005). Informe sobre el tratamiento informativo en los medios de comunicación respecto de las víctimas del terrorismo. Resolución 2005/1, 2 de marzo.

http://www.comisiondequejas.com/wp-content/uploads/1. $p d f$

CPC-CIC (2006). Código deontológico. Declaración de principios de la profesión periodística en Cataluña. Barcelona: Col-legi de Periodistes de Catalunya.

https://fcic.periodistes.cat/wp-content/uploads/2018/02/ codi-deontologic_CPC_CIC_castella\%CC\%80_BAIXA_GEN.pdf

Cruz-Álvarez, Jesús; Suárez-Villegas, Juan-Carlos (2017). "Pautas deontológicas para el periodismo digital". El profesional de la información, v. 26, n. 2, pp. 249-254. https://doi.org/10.3145/epi.2017.mar.11

Dayan, Daniel; Katz, Elihu (1992). Media events: The live broadcasting of history. Cambridge, MA: Harvard University Press. ISBN: 9780674559561

Díaz-Campo, Jesús (2006). "Códigos éticos del periodismo latinoamericano". En: Marcos, Luís-Humberto (coord.). As profissões da comunicação. VII Ibercom. Portugal: Asslbercom, pp. 516-524. ISBN: 9789729048227

Díaz-Campo, Jesús; Segado-Boj, Francisco (2015). “Journalism ethics in a digital environment: How journalistic codes of ethics have been adapted to the internet and ICTs in countries around the world". Telematics and informatics, v. 32, n. 4, pp. 735-744.

https://doi.org/10.1016/j.tele.2015.03.004

El país (2017a). “La policia de Barcelona: 'L’autor és un individu d'un metre setanta"'. El país, 17 agosto. https://cat.elpais.com/cat/2017/08/17/videos/1502985327_834067. html

El país (2017b). "Terroristas muertos". El país, 17 agosto. https://elpais.com/elpais/2017/08/17/opinion/1502994383_082737. html

El país (2017c). "Así fue abatido el quinto terrorista de Cam- 
brils". El país, 18 agosto.

https://elpais.com/elpais/2017/08/18/videos/1503057854_819526. html

El país (2017d). "Todos los escenarios de los atentados en Cataluña". El país, 18 agosto.

https://politica.elpais.com/politica/2017/08/18/ actualidad/1503046060_624899.html

El periódico (2017a). "Identificado el presunto terrorista que alquiló la furgoneta del ataque en La Rambla". El periódico, 17 agosto.

https://www.elperiodico.com/es/barcelona/20170817/ identificado-el-terrorista-que-alquilo-la-furgoneta-delataque-en-la-rambla-de-barcelona-6229276

El periódico (2017b). "Las fotos del atentado de Barcelona". El periódico, 17 agosto.

https://www.elperiodico.com/es/barcelona/20170817/ fotos-atentado-barcelona-6229002

Galán, Javier; Alameda, David (2017). "El yihadismo ha causado más de 600 muertos en la UE desde 2004". El país, 17 agosto.

https://politica.elpais.com/politica/2017/08/17/ actualidad/1502997944_144229.html

García, Elsa (2017). “Diez años de internamiento, pena máxima para el terrorista autor del atropello si es menor". El país, 18 agosto.

https://politica.elpais.com/politica/2017/08/18/ actualidad/1503057964_467095.html

García, Jesús; Piñol, Àngels; Güell, Oriol (2017). “Los mossos abaten a cinco terroristas que planeaban una nueva masacre en Cambrils". El país, 18 agosto.

https://elpais.com/ccaa/2017/08/18/catalunya/1503014552_393278. html

Gerbner, George (1988). Violence and terror in the mass media. Reports and papers on mass communication, n. 102. Paris: Unesco. ISBN: 923102603

http://unesdoc.unesco.org/images/0008/000826/082684eo. $p d f$

Höijer, Birgitta (2004). "The discourse of global compassion: The audience and media reporting of human suffering". Media, culture \& society, v. 26, n. 4, pp. 513-531. https://doi.org/10.1177/0163443704044215

Hoskins, Andrew; Awan, Akil; O'Loughlin, Ben (2011). Radicalisation and the media: Connectivity and terrorism in the new media ecology. London: Routledge. ISBN: 9780 41555035

Houston, Brian (2009). "Media coverage of terrorism: A meta-analytic assessment of media use and posttraumatic stress". Journalism \& mass communication quarterly, v. 86, n. 4, pp. 844-861.

https://doi.org/10.1177/107769900908600408

Jenkins, Simon (2017). "Barcelona is Europe's seventh vehicle attack in a year. What can be done?". The guardian, August $18^{\text {th }}$.

https://www.theguardian.com/commentisfree/2017/ aug/18/barcelona-attack-europe-seventh-vehicle-what-done
Jones, Clement J. (1980). Mass media codes of ethics and councils. Reports and papers on mass communication, n. 86 . Paris: Unesco. ISBN: 9231071152

http://unesdoc.unesco.org/images/0004/000423/042302Eo. $p d f$

Keinan, Giora; Sadeh, Avi; Rosen, Sefi (2003). "Attitudes and reactions to media coverage of terrorist acts". Journal of community psychology, v. 31, n. 2, pp. 149-165. https://doi.org/10.1002/jcop.10040

Keith, Susan; Schwalbe, Carol B.; Silcock, B. William (2006). "Images in ethics codes in an era of violence and tragedy". Journal of mass media ethics, v. 21, n. 4, pp. 245-264. https://doi.org/10.1207/s15327728jmme2104_3

Konow-Lund, Maria; Olsson, Eva-Karin (2017). "Social media's challenge to journalistic norms and values during a terror attack". Digital journalism, v. 5, n. 9, pp. 1192-1204. https://doi.org/10.1080/21670811.2016.1243990

Laitila, Tiina (1995). "Journalistic codes of ethics in Europe". European journal of communication, v. 10, n. 4, pp. 527-544. https://doi.org/10.1177/0267323195010004007

Marcos, José (2017). "Los terroristas no son nada religiosos". El país, 18 agosto.

https://politica.elpais.com/politica/2017/08/18/ actualidad/1503067330_392555.html

Marthoz, Jean-Paul (2017). Terrorism and the media. A handbook for journalists. Paris: Unesco. ISBN: 9789231001994 http://unesdoc.unesco.org/images/0024/002470/247074E. $p d f$

Matthews, Julian (2016). "Media performance in the aftermath of terror: Reporting templates, political ritual and the UK press coverage of the London Bombings, 2005". Journalism, v. 17, n. 2, pp. 173-189. https://doi.org/10.1177/1464884914554175

Merolla, Jennifer; Zechmeister, Elizabeth (2009). Democracy at risk: How terrorist threats affect the public. Chicago: University of Chicago Press. ISBN: 9780226520568

Moeller, Susan (2009). Packaging terrorism: Co-opting the news for politics and profit. New Jersey: Wiley-Blackwell. ISBN: 9781405173650

Mogensen, Kirsten (2008). "Television journalism during terror attacks". Media, war \& conflict, v. 1, n. 1, pp. 31-49. https://doi.org/10.1177/1750635207087624

Nacos, Brigitte (1994). Terrorism \& the media. New York: Columbia University Press.

Nacos, Brigitte (2002). Mass-mediated terrorism: The central role of the media in terrorism and counterterrorism. London: Rowman \& Littlefield. ISBN: 9780742510821

Nacos, Brigitte (2016). Mass-mediated terrorism: mainstream and digital media in terrorism and counterterrorism. Lanhan, Maryland: Rowman \& Littlefield.

Nagar, Na'ama (2010). "Who is afraid of the T-word? Labeling terror in the media coverage of political violence before and after 9/11". Studies in conflict \& terrorism, v. 33, n. 6, pp. 533-547. 


\section{https://doi.org/10.1080/10576101003752655}

Norris, Pippa; Kern, Montagne; Just, Marion (eds.) (2003). Framing terrorism: The news media, the government, and the public. New York: Routledge. ISBN: 9780415947190

Nossek, Hillel (2008). "News media'-media events: Terrorist acts as media events". Communications, v. 33, n. 3, pp. 313330.

https://doi.org/10.1515/comm.2008.020

Núñez-Villaverde, Jesús A. (2017). "Y ahora Barcelona". El periódico, 17 agosto.

https://www.elperiodico.com/es/opinion/20170817/yahora-barcelona-6229439

Paletz, David L.; Schmid, Alex P. (eds.) (1992). Terrorism and the media. London: Sage. ISBN: 9780803944831

Rivas-Nieto, Pedro; Plaza, Juan F. (2015). "Pautas para la cobertura periodística de actos terroristas. Propuesta de un modelo informativo de responsabilidad democrática". Estudios sobre el mensaje periodístico, v. 21, n. 2, pp. 1207-1223. https://doi.org/10.5209/rev_ESMP.2015.v21.n2.50911

Rodríguez-Martínez, Ruth; López-Meri, Amparo; Merino-Arribas, Adoración; Mauri-Ríos, Marcel (2017). "Instrumentos de rendición de cuentas en España. Análisis comparativo en Cataluña, Galicia, Madrid y Valencia". El profesional de la información, v. 26, n. 2, pp. 225-266.

https://doi.org/10.3145/epi.2017.mar.12

Sánchez, Guillermo (2017). "Los mossos rodean un bar donde los terroristas retienen a rehenes". El periódico, 17 agosto.

https://www.elperiodico.com/es/barcelona/20170817/losmossos-rodean-un-bar-donde-los-terroristas-retienen-arehenes-6229084

Sánchez-Duarte, José-Manuel (2009). "Narrativas y portavoces del terrorismo mediatizado". Revista latina de comunicación social, v. 12, n. 64.

https://doi.org/10.4185/RLCS-64-2009-839-481-490

Schudson, Michael (2002). "What's unusual about covering politics as usual". En: Zelizer, Barbie; Allan, Stuart (eds). Journalism after September 11. London: Routledge, pp. 3647. ISBN: 9780415460156

Seib, Philip (2016). Beyond the front lines: How the news media cover a world shaped by war. London: Palgrave Macmillan. ISBN: 9781403972088

Seib, Philip; Janbek, Dana (2010). Global terrorism and new media: The post Al-Qaeda generation. London: Routledge. ISBN: 9780415779623

Shoshani, Anat; Slone, Michelle (2008). "The drama of media coverage of terrorism: Emotional and attitudinal impact on the audience". Studies in conflict \& terrorism, v. 31, n. 7, pp. 627-640.

https://doi.org/10.1080/10576100802144064
Spencer, Alexander (2010). The tabloid terrorist: The predicative construction of new terrorism in the media. London: Palgrave-McMillan. ISBN: 9781349365692

Suárez-Villegas, Juan-Carlos (2015a). "Ethical and deontological aspects of online journalism. Their perception by journalists". Revista latina de comunicación social, v. 70, pp. 90-109.

https://doi.org/10.4185/RLCS-2015-1036en

Suárez-Villegas, Juan-Carlos (2015b). "La Comisión de deontología como referente de la autorregulación del periodismo: apuntes doctrinales sobre el periodismo digital". Comunicación y sociedad, v. 28, n. 3, pp. 135-150. https://doi.org/10.15581/003.28.3.sp.135-150

Tester, Keith (2001). Compassion, morality, and the media. Buckingham, Philadelphia: Open University Press. ISBN: 978 0335205134

The guardian (2017). "Aftermath of attack on Las Ramblas in pictures". The guardian, August $17^{\text {th }}$.

https://www.theguardian.com/world/gallery/2017/ aug/17/barcelona-terror-attack-in-pictures

Tremlett, Giles; Rankin, Jennifer; Borger, Julian; Burgen, Stephen (2017). "Cambrils: Five terror suspects killed as second attack follows Las Ramblas". The guardian, August $18^{\text {th }}$.

https://www.theguardian.com/world/2017/aug/17/vancrashes-into-crowd-of-people-barcelona-las-ramblas

Vara, Alfonso; Rodríguez-Virgili, Jordi; Giménez, Elea; Díaz, Montserrat (eds.) (2006). La comunicación en situaciones de crisis: del 11-M al 14-M. XIX Congreso internacional de comunicación. Pamplona: Eunsa. ISBN: 8431323744

Weimann, Gabriel (1983). "The theater of terror: Effects of press coverage". Journal of communication, v. 33, n. 1 , pp. 38-45

https://doi.org/10.1111/j.1460-2466.1983.tb02372.x

Weimann, Gabriel (1987). "Media events: The case of international terrorism". Journal of broadcasting \& electronic media, v. 31, n. 1, pp. 21-39.

https://doi.org/10.1080/08838158709386643

Weimann, Gabriel (2008). "The psychology of mass-mediated terrorism". American behavioral scientist, v. 52, n. 1, pp. 69-86.

https://doi.org/10.1177/0002764208321342

Weimann, Gabriel; Winn, Conrad (1994). The theatre of terror. Mass media and international terrorism, New York: Longman. ISBN: 9780801311017

Yarchi, Moran; Galily, Yair; Tamir, Ilan (2015). "Rallying or criticizing? Media coverage of authorities' reaction to terror attacks targeting sporting events". Studies in conflict \& terrorism, v. 38, pp. 1008-1021. https://doi.org/10.1080/1057610X.2015.1076644 